\title{
EL URBANISMO NEOCLASICO DE IGNACIO DE CASTERA
}

\author{
$\mathbf{P} \mathbf{O} \mathbf{R}$
}

FRANCISCO DE LA MAZA

SABIDO es que el Virrey Conde de Revillagigedo fué de los pocos gobernantes, y el que más se preocupó por limpiar, engrandecer y embellecer a la ciudad de México.

A principios del año de 1794 nombró a su arquitecto consentido, Ignacio de Castera, para que limpiase los barrios de la ciudad, los más sucios por su trazo irregular y la proverbial incuria de sus habitantes, que más que descuido era pobreza.

Castera desplegó inmediatamente su gran actividad, comunicándole al Virrey, en marzo de ese año, que habia tomado casa y corral y había construido una galera cubierta de tejamanil de más de cien varas, con su correspondiente pajar, el cebadero y las demás oficinas. Tenía ya habilitados treinta y dos carros para la basura y ciento y tantas parihuelas para el transporte de la misma a los carros en donde éstos no podían entrar. Se acordó Castera de los callejones estrechos, los del estilo del de "Sal si puedes" y previó el caso. Las parihuelas eran de madera de encino y cubiertas de cuero.

Al ocuparse de estos menesteres iniciales, Castera se dió cuenta cabal "de la irregularidad con que se hallan las casas de los barrios, suma estrechez e inversión de sus callejones" por lo que concluía: "están por demás las providencias más eficaces para establecer el buen orden de su limpieza". 
Pero no se quedó el arquitecto con las eficaces providencias para el aseo, sino que concibió todo un proyecto urbanístico para arreglar a la ciudad de México de una manera permanente y definitiva, un verdadero "Plano Regulador", que parece ser el primero que se pensó en México.

"He meditado un arbitrio -escribe al Conde- que, siendo en mi concepto $\tan$ hermoso, $\tan$ cómodo, $\tan$ útil, $\tan$ económico, tan grande $\mathrm{y}$ perfecto en todas sus partes, que estoy por creer que no se puede mejorar." Nada modesto se presenta Castera en este párrafo, pero su entusiasmo y su devoción por la ciudad de México aminoran su petulancia. Además tenía razón, como veremos.

Parece que meditó sus palabras y, aun cuando no las borró, se creyó obligado a añadir: "Todo se debe a Vuestra Excelencia, porque aspirando sus desvelos, no sólo a conseguir la limpieza material de los barrios, sino también a la extirpación de las muchas maldades que la expresada irregularidad, malos pasos, estrechez y escondrijos ocasionan, y todo esto con el menor costo posible y establecido de una manera que pueda perpetuarse. Enseñado pues por Vuestra Excelencia y ocupado de estos mismos sentimientos de humanidad y grandeza e inflamado con ellos, he meditado la mayor obra que, en comparación de sus ventajas, no puede reducirse a menos costo ni a mayor perfección." $Y$ añade zalamero $y$ sentencioso: "Si se verifica, puede Vuestra Excelencia llamarse con muchísima propiedad el restaurador de la indisputable hermosura de las calles de esta Ciudad, ya que la idea es bien simple (como lo manifiesta el adjunto plano); la ejecución también es fácil (aunque muy laboriosa $\mathrm{y}$ de mucho trabajo personal), pero todo esto y los costos con que ofrezco contribuir, lo sacrifico muy gustoso por ver efectuada una idea tan noble y debida al excelente influjo de Vuestra Excelencia."

Las ideas urbanísticas de Castera, según la exposición del plano, eran las siguientes:

1. El proyecto es "hermoso" porque la continuación, en línea recta implacable, de las calles del centro, atravesando sin misericordia los barrios, le daría un aspecto de limpieza y de novedad.

2. Las nuevas calles así abiertas, que antes eran de 1,700 varas, quedarian de 3,300 hasta su límite máximo o sea un gran cuadro que se trazaría alrededor de la ciudad. "Así las calles - dice- podrán transitarse a pie, a caballo $y$ en coche la infinidad de casas de los barrios y fabricarse otras de campo en los grandes prados que resultan en su cir- 
cunferencia y demuestra el color verde, teniendo en su recinto las casas de recreo que a tanta costa e incomodidad tienen los habitantes de posibles (con el fin de tener algún desahogo) en los pueblos distantes."

3. El cuadro circundante, límite de la ciudad, tendría 13,200 varas "hasta la Acequia Maestra, que en figura cuadrada y circunferencia de 13,200 varas ha de ser término de sus calles, recipiente de sus aguas, circulación de ellas por lo interior de sus tarjeas y navegación de sus comestibles y materiales". El centro geográfico de este gran cuadro sería la Catedral y la Acequia Maestra "es la que perfecciona esta obra, la que cierra el cuadro que ha de formar el plano de esta ciudad, la que da términos a las manzanas de sus casas y calles que las forman, la que ha de recibir en todos los puntos o bocacalles (las letras A), las aguas de servidumbre y temporales por lo interior cuando vayan teniendo tarjeas, y por lo exterior aunque no las tengan, a cuyo fin, demolidas las casas que impiden la línea, si no hay tarjea que continuar de las que están en el centro de la ciudad, se hace sólo un caño empedrado para la segura corriente de las aguas..." Las letras marginales del cuadro: B, C y D, serian compuertas para manejar las aguas de Chapultepec y Mexicalcingo.

4. La ventaja de esta decidida apertura rectilínea de las calles sería que sólo con ella se podría hacer la numeración de sus manzanas, el registro de habitantes, el tránsito de las rondas, la "decente y debida ministración del Viático (que casi en todos los barrios es menester conducir a Su Majestad por el ministro a pie por mil atascaderos inmundos y peligrosos)".

5. Económicamente hablando le parecía a Castera que el costo de la limpieza sería mucho menor y que se aumentarian considerablemente las rentas del Ayuntamiento "con el dominio de los terrenos que resulten por hallarse abandonados e incultos".

6. Podria asignarse, con esta nueva urbanística, los lugares adecuados a los curtidores, tintoreros, herreros, hornos y zahurdas " $y$ otras oficinas nocivas en lo interior de una gran población y que, con ventajas de sus interesados, puedan irse estableciendo a la margen de la Acequia Maestra".

7. Las casas que tuvieran que demolerse serían pagadas por el Estado y en el caso de edificios de valor, Castera propone "se dejen como están continuando con la línea de la calle para que en este estado preci- 
samente se renueven cuando llegue el caso de su ruina, alineando en los terrenos eriazos la línea de las calles, poniéndole sus partes, número y nombre (que deberá ser el de Vuestra Excelencia) para que expeditos los terrenos en que puede ya libremente continuar las manzanas de casas, sean todos aquellos que resulten libres, compensación de los que se disminuyan y corten y igualmente se pueden mercedar o vender".

8. Propone se comience con 30,000 pesos la apertura de las calles "porque no pudiéndose ni debiéndose poner de pronto la perfecta abertura en línea de estas calles, porque sería de considerable costo, bastará que se haga lo expuesto y alcanzará con 30,000 pesos", de los cuales él mismo ponía 15,000 que ahorraría de los costos de la limpieza con la nueva urbanística. $\mathrm{Y}$ prosigue: "Con estos 30,000 pesos (que de ningún modo quiero que entren en mi poder) se han de ir pagando los edificios que señale, derrumbes, terraplenes (en que pueden ocuparse los presos) y đemás gastos indispensables al fin."

9. La Junta de Policía de la ciudad deberia hacer la justificación de los derrumbes de casas y su avalúo para pagarlos a sus dueños.

10. Una cosa muy importante era la construcción de las atarjeas o "tarjeas" del desagüe "para la sanidad del pueblo", para lo cual calculó, aparte de los 30,000 pesos, otros 140,000 , y asi quedarian "con su corriente interior, exterior y circulación rápida y limpia de sus aguas, sin necesidad de más obras hasta cubrir este suplemento".

El presupuesto en detalle sería el siguiente:

"Por 13,500 varas de zanja de 8 varas de latitud y 2 de profundidad, desde sus bordes, a peso: 13,500 pesos.

"Por 4,000 pesos que puede importar el derrumbe y compra de las casas que por San Diego, San Hipólito y Santa Ana es indispensable comprar para el efecto, siendo estos los parajes más acomodados y en que tienen menos valor los edificios: 4,000 pesos.

"Por 8 puentes a 500 pesos en los parajes $F$ (los que salen al Paseo Nuevo, Calzada de la Piedad, Calzada de San Antonio, Paseo de Revillagigedo, Calzada de San Lázaro, Calzada de Guadalupe, uno que pasaría detrás del convento de San Fernando y otro en la Calzada de San Cosme: 4,000 pesos.

"Por dos compuertas mayores y tres menores en los parajes $\mathrm{B}$ y $\mathrm{E}$, (las dos esquinas del cuadro y otra enmedio, al lado poniente) : 2,000 pesos. 


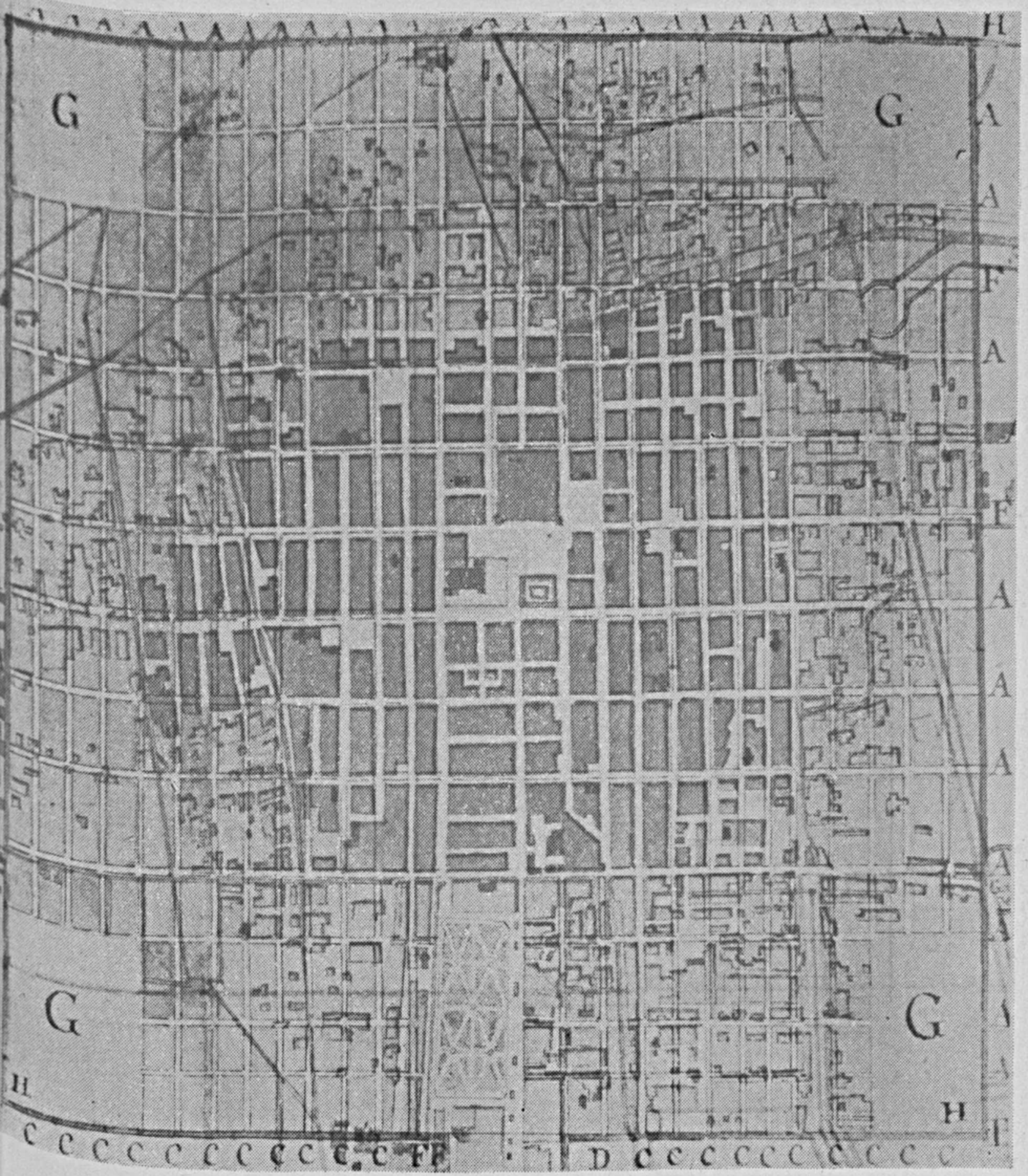

1. Ignacio de Castera. Plano de 1794 en el Archivo General de la Nación. 


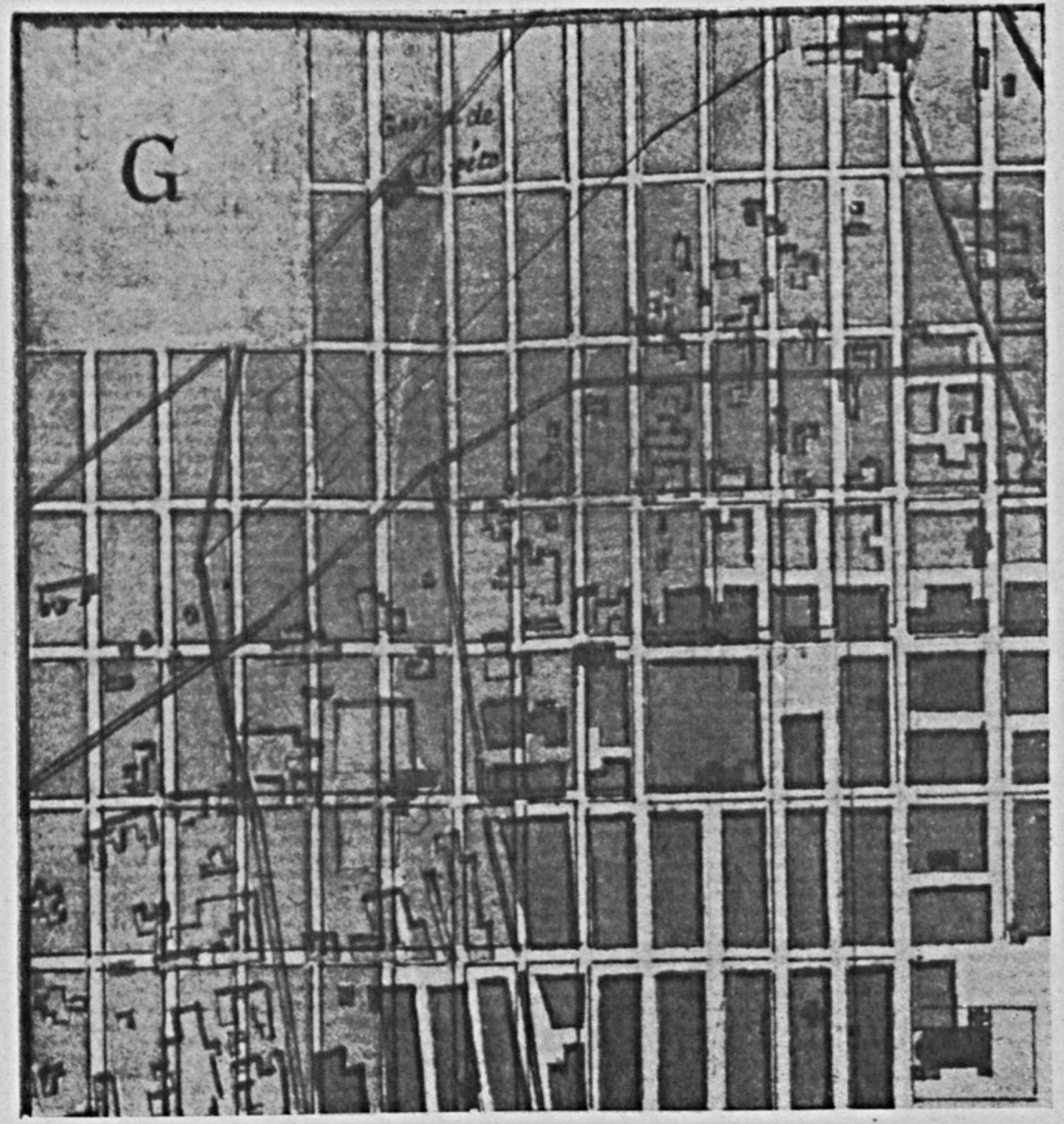

2. Plano de Castera. Angulo Noreste. 


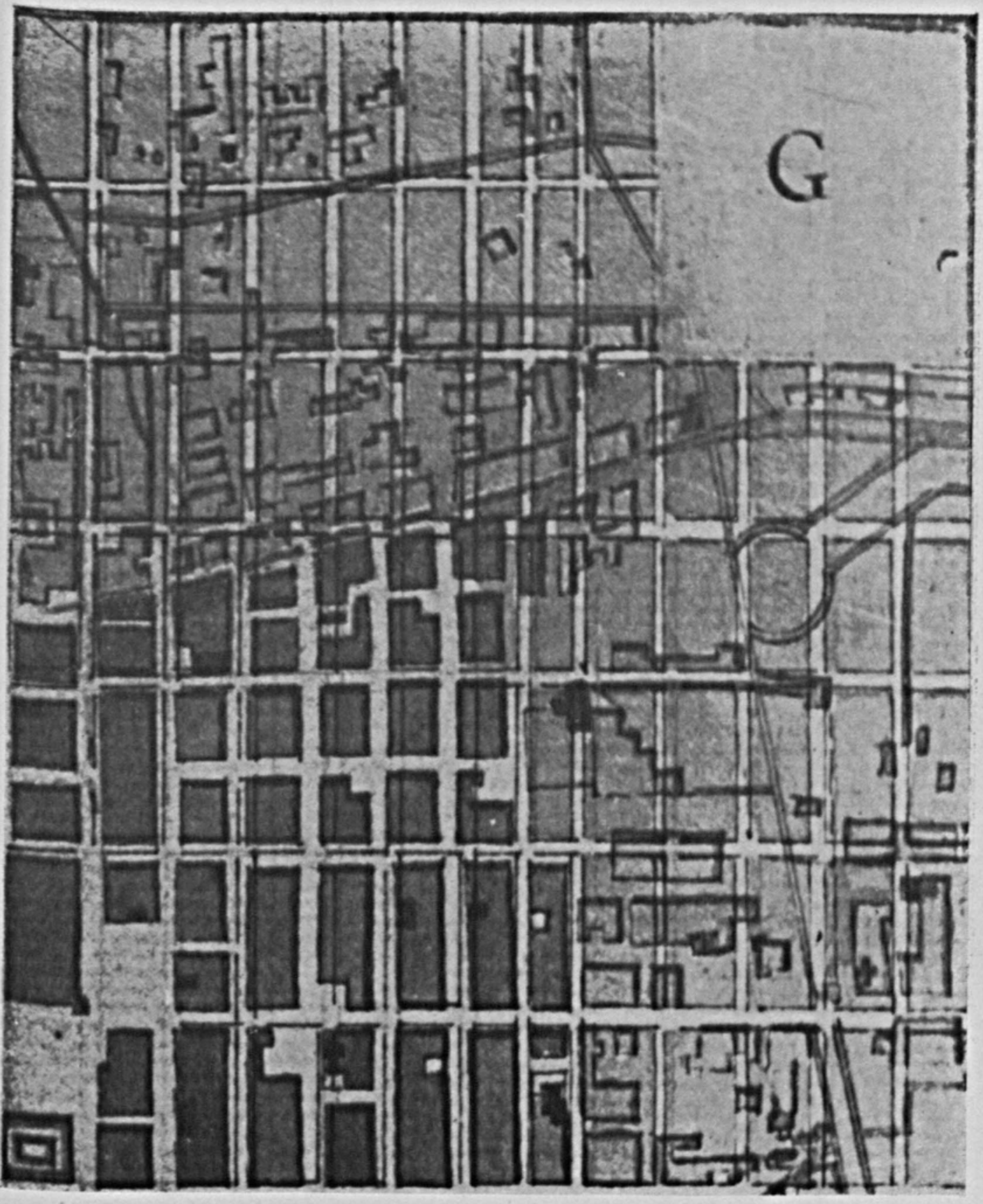

3. Plano de Castera. Angulo Sureste. 
DOI: http://dx.doi.org/10.22201/iie.18703062e.1954.22.569

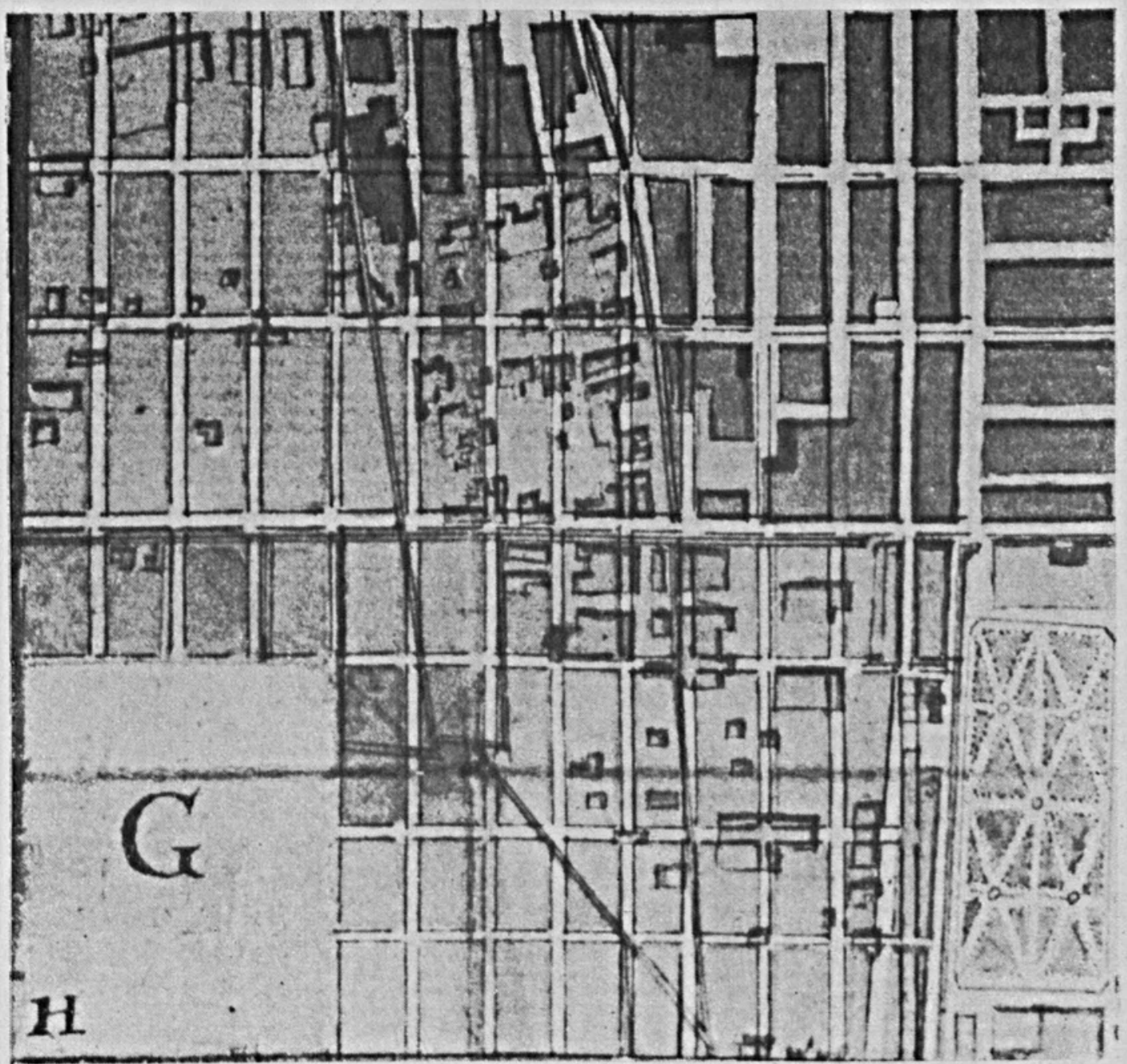

4. Plano de Castera. Angulo Noroeste. 


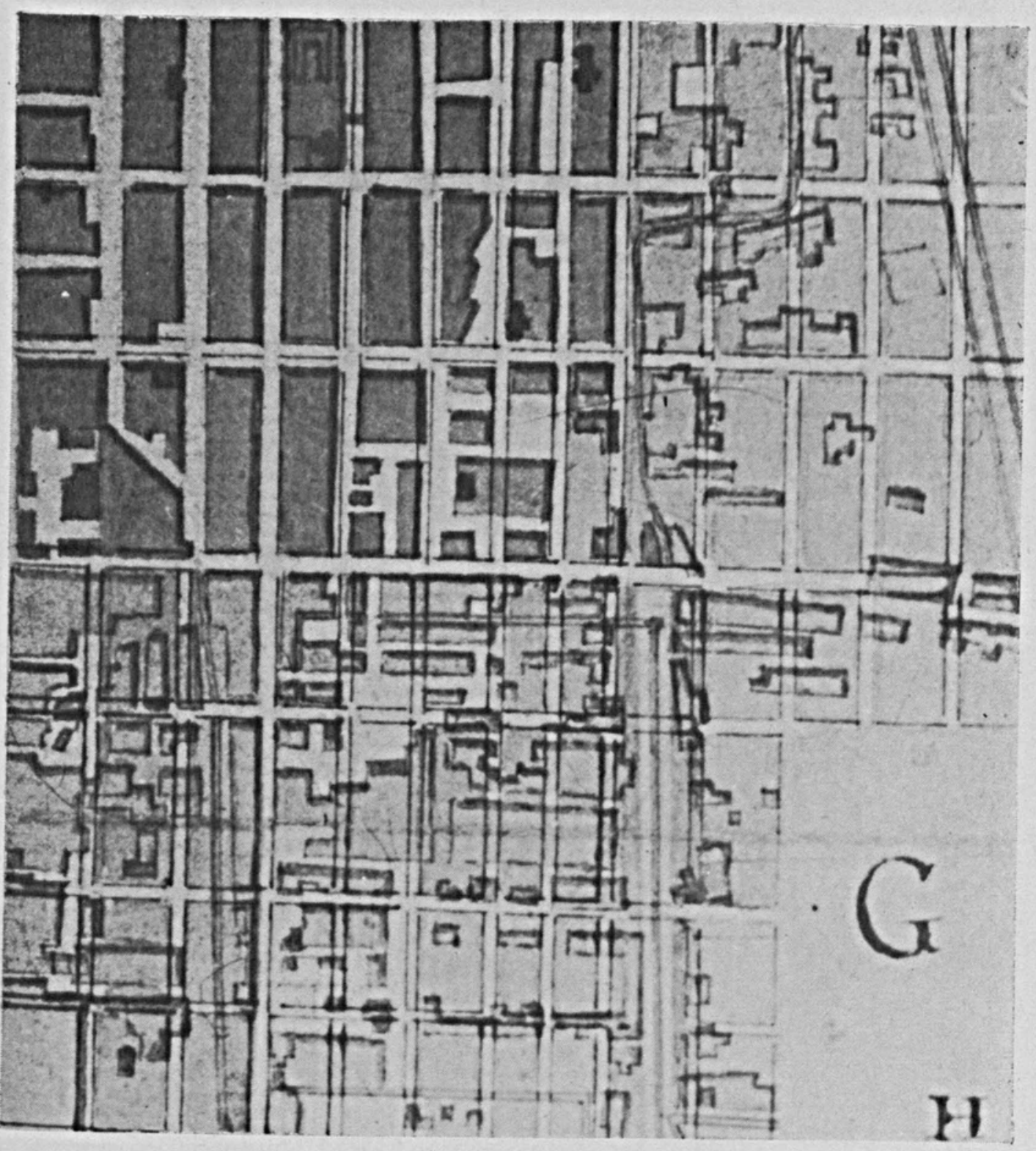

5. Plano de Castera. Angulo Suroeste. 


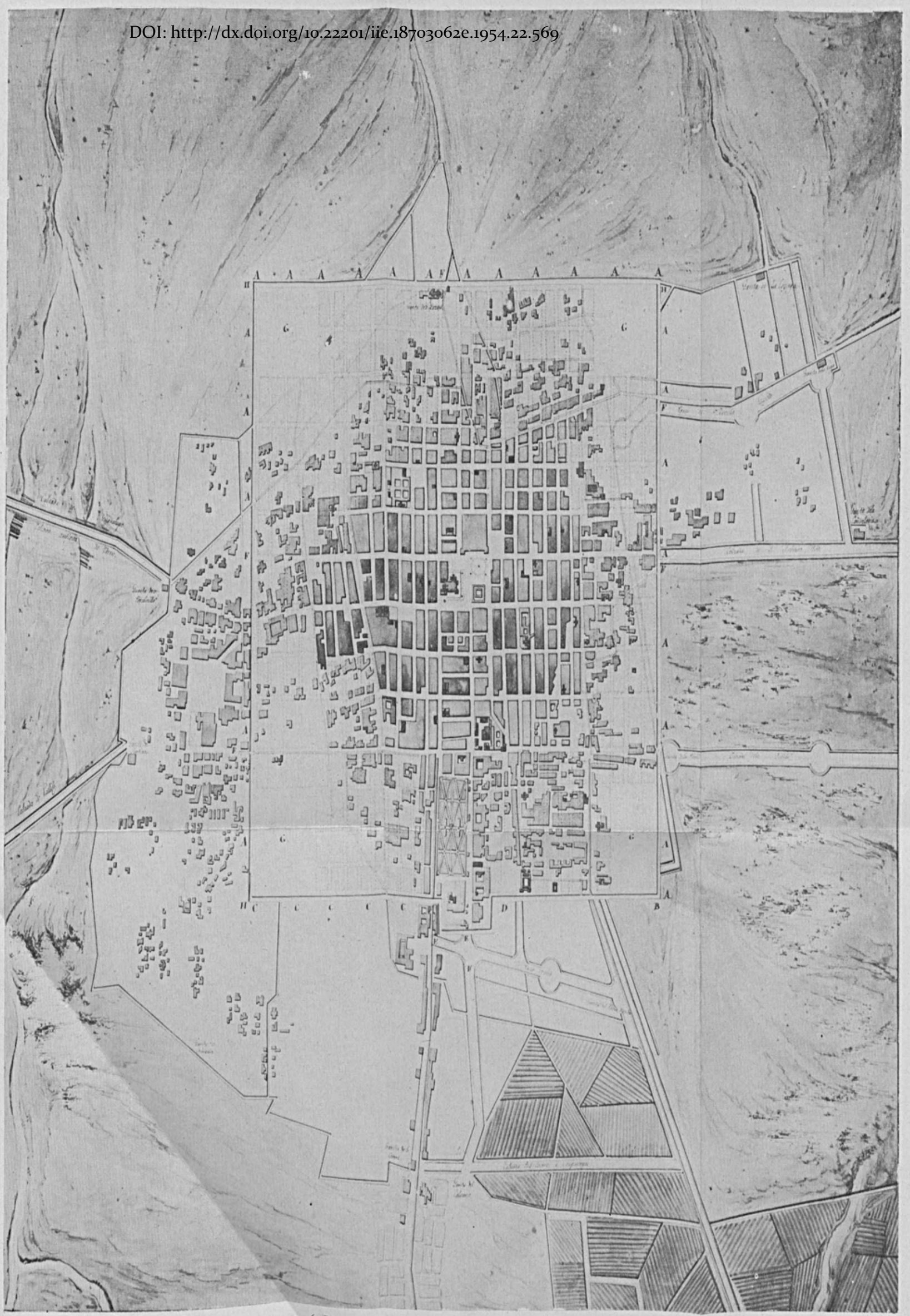




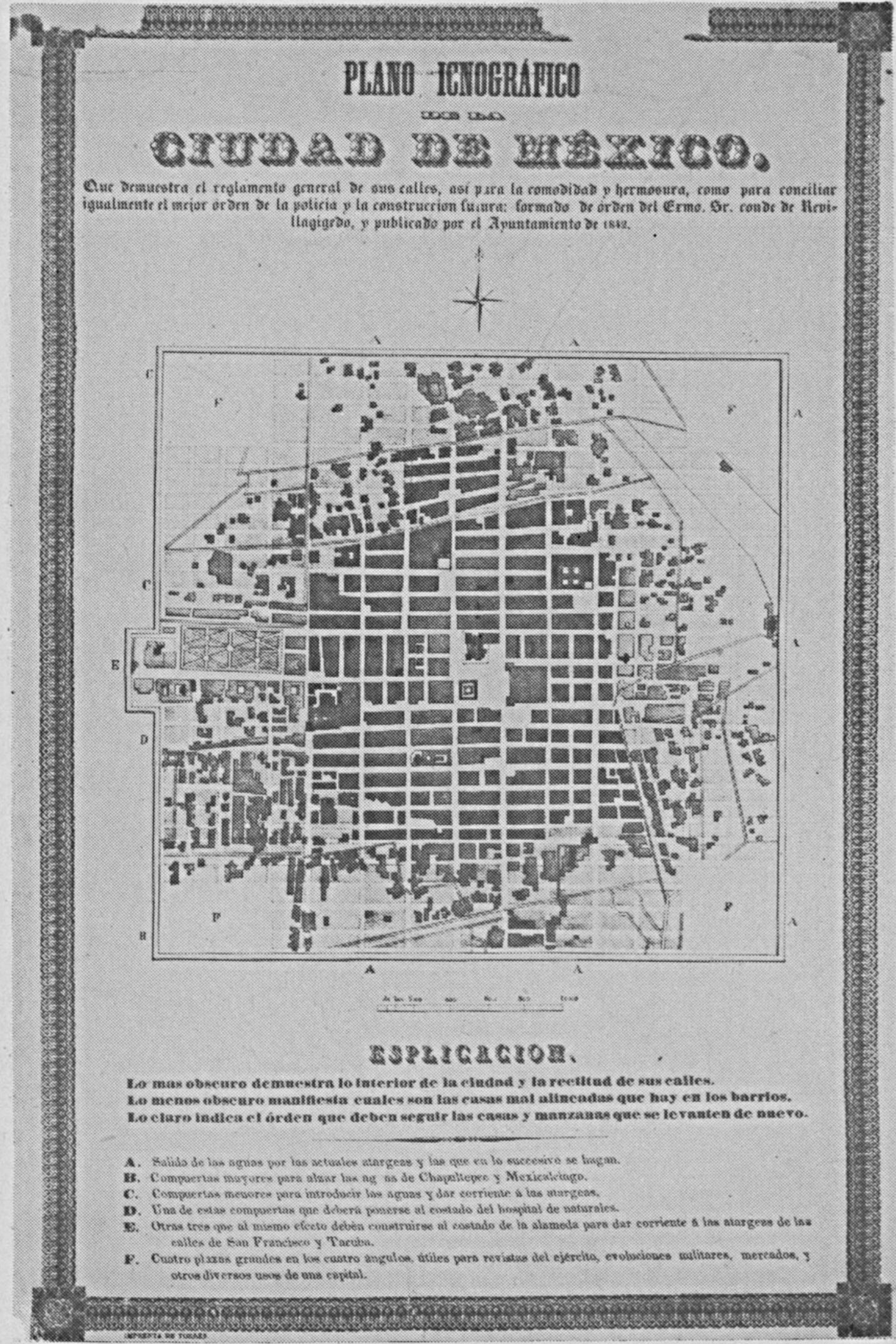

7. Plano de Castera. Impresión de 1842. Instituto de Geografía. Tacubaya. 


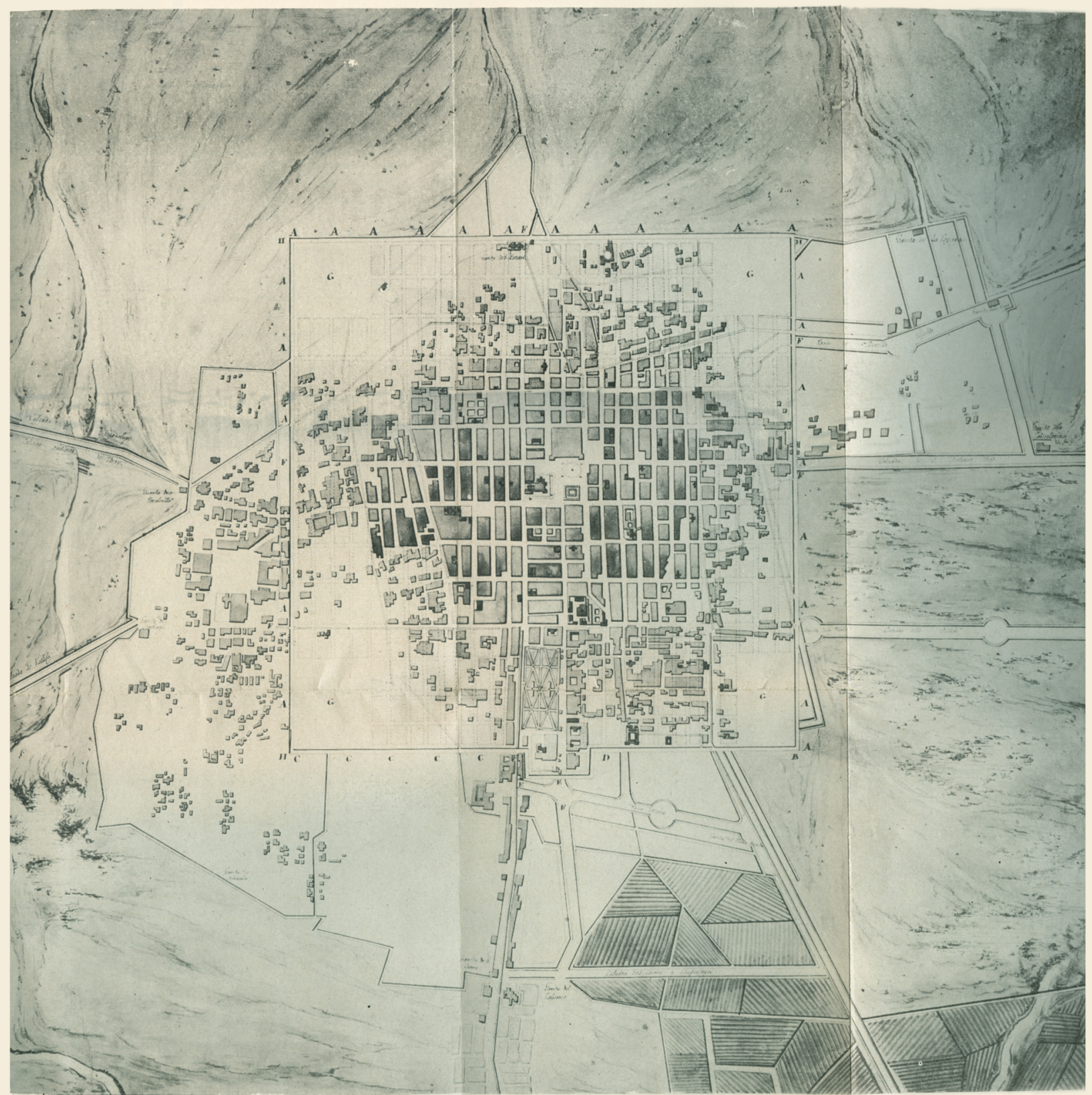


"Por un puente en el camino de San Agustín de las Cuevas, limpia y apertura de las zanjas en el paraje de las Animas y Hacienda de los Portales, para la introducción perenne de aguas de Mexicalcingo en su antigua compuerta donde hay una casa buena y firme: 3,000 pesos."

El total era de 26,500 , con un ahorro para cualquier "gastillo" imprevisto.

E1 plano lleva la siguiente inscripción: "Plano Iconográfico de la - Ciudad de México que demuestra el reglamento general de sus calles, asi para la comodidad y hermosura, como para la corrección y extirpación de las maldades que hay en sus barrios, por la infinidad de sitios escondidos, callejones sin tránsito, ruinas y paderones (sic) que las ocasionan a pesar del celo de los Justicias de orden del Exmo. Sr. Conde (de) Revillagigedo. Por el Mro. Mayor Dn. Ignacio de Castera. Año de 1794."

El plano es a colores, de $65 \mathrm{~cm}$. $\ 47 \mathrm{~cm}$. "Lo encarnado demuestra lo interior de la Ciudad y que están sus calles rectas" (la parte central). "Lo amarillo las casas mal formadas que hay en los barrios" (las partes laterales del cuadro central). "Los cuadros verdes claros las situaciones - manzanas de casas que deben irse formando" (las manzanas vacias alrededor del centro y llegando a las rectas del gran cuadro). "Lo blanco las calles que existen y deben continuar en línea recta con éstas" (toda la cuadrícula de calles).

Las letras "A" son "las salidas de las aguas por esas calles y tarjeas hechas y que se vayan haciendo".

Las letras " $\mathrm{B}$ " son "las compuertas mayores para alzar las aguas de Chapultepec y Mexicalcingo".

Las letras " $\mathrm{C}$ " son "las compuertas menores para introducirlas $\dot{y}$ darles una impulsada corriente a las tarjeas".

La letra " $D$ " es "una de estas compuertas que ya se va a poner en la tarjea que se está haciendo por el costado del Hospital Real".

Las letras "E" son otras tres compuertas "que asimismo se pueden establecer para el mismo efecto por los costados de la Alameda para dar corriente a las tarjeas principales de las calles de San Francisco y Tacuba".

Las letras " $F$ " son "ocho puentes que se necesitan para dar entrada a esta ciudad y las calzadas a sus calles principales".

Las letras "G" son "cuatro grandes plazas en los cuatro ángulos para la disciplina de las tropas, suplicios militares, maestranzas, carreras y otra infinidad de usos utilisimos que puede hacerse de ellas y frecuentemente ocurren en una ciudad grande". 
Las letras " $\mathrm{H}$ " los cuatro ángulos o extremos de la Acequia Maestra.

Castera habia hecho otros planos de México anteriores a éste. Uno, de 1776 , es el "Plano geométrico de la imperial, noble y leal ciudad de México, teniendo por extremo la zanja y garitas de resguardo de la Real Aduana, sacado de orden del Señor don Francisco Leandro de Viana, Conde de Teja, oidor que fué de la Real Audiencia de México y hoy del Consejo y Cámara de Indias: Por D. Ignacio de Castera. Año de 1776. Dale a luz D. Tomás López, geogr., de los Dominios de S. M. Año de 1785." Es un grabado en cobre. De este plano hizo otro, modificado, don Manuel Ignacio de Jesús del Aguila, en 1792, iluminado a la acuarela, existente en el Archivo General de la Nación, Ramo de Historia, tomo xIv, y otros dos, uno del mismo año, "semiluminado" y con algunas modificaciones, y otro de 1794 "fielmente copiado y delineado e iluminado de su mano".

En 1793 hizo "Plano Ighnográfico de México que demuestra su centro principal y barrios, formado para fijar el término de estos y establecer el buen orden de su limpia. Por el Maestro Mayor D. Ignacio Castera. Año de 1793", en el Archivo General de Indias.

Respecto del plano que nos ocupa, que es el existente en el Archivo General de la Nación, Ramo de Obras Públicas, Vol. 2, Exp. 1, hay varias copias; una, igual, en el Archivo del Ayuntamiento, en Planos de la Ciudad de México, Vol. 3615, Leg. 1, Exp. 6, y otras más, con variantes, así como su impresión en una hoja suelta por el Ayuntamiento de 1842 y por don Alberto Ma. Carreño en su estudio: La Arquitectura y la Ingeniería Coloniales (1918) y en Obras Públicas... Organo del Departamento del Distrito Federal de México (1930), sin mayores comentarios. 1

De este plano hizo inmediatamente otro Castera, "para que con arreglo al nuevo alineamiento de calles se establezca la pensión de la contribución que deben hacer los dueños de fincas para la contribución y subsistencia de los empedrados..." en 24 de junio de 1794, y el "Plano Iconográfico que demuestra el reglamento general de sus calles, así para la comodidad y hermosura, como igualmente conciliar el mejor orden de Policía y construcción futura".

Pasó el plano a aprobación del Ayuntamiento y de la Junta de Policía y el Fiscal dijo: "que aunque no se puede dudar de las convenien-

1 Véase Manuel Carrera Stampa. Planos de la Ciudad de México. "Boletín de la Sociedad Mexicana de Geografía y Estadística", t. Lxvr, Nos. 2 y 3, pp. 362 a 365. 
cias y utilidades del proyecto es forzoso instruir el expediente con las formalidades necesarias para que recaiga la superior resolución de V. E. con el debido conocimiento y acierto que tanto desea en todas sus determinaciones". E1 28 de abril fué la junta y el Síndico dijo que la idea de Castera la parecía magnífica y "que hasta ahora parecía tocar en la esfera de lo imposible" pero que "lo detiene la reflexa de que el proyecto necesita de más maduro examen, pues recela que acaso parezca que por el juicio de un solo perito se expongan los caudales del público a tener un éxito contingente". Se resolvió que pasara a dos peritos, que resultaron el agrimensor José Burgaleta y Miguel Constanzó, eterno censor de todo cuanto se hacía en México.

Contestaron ambos que "Ias miras del maestro Castera son dignas de todo elogio; en cuanto a la vista, ornato $y$ hermosura que ha de proporcionar la ejecución del pensamiento es punto en que han de convenir todos", pero que había que tener presente los costos que originarian la compra de casas, el acarreo de material y, sobre todo, el costo de la gran acequia con que se intentaba "ceñir" a la ciudad y, prudentemente, aconsejan que si va a costar un peso cada vara, que se hagan algunos metros para ver si es cierto.

Peza, el Procurador General, confió sólo en Castera y decidió no se hiciese caso de los maestros, declarando que "no hay duda en que la completa abertura de las calles de los barrios seria muy costosa por algunos edificios valiosos, pero como por ahora sólo se ha de verificar con los de menor valor, quedando los otros sin que se haga novedad en ellos hasta que, porque haya de hacer su reedificación cuando lo necesiten..." y sigue copiando, mal por cierto, lo dicho por Castera.

Sin embargo, las desconfiadas autoridades pidieron que viera el plano el arquitecto don José del Mazo y Avilés y, suplican al Virrey en su escrito, que es del 16 de julio, no deje a Castera que siga anticipándose a su proyecto en demoler casas. El enérgico Castera, que siempre contó con la aprobación del Conde de Revillagigedo, ya había comenzado su obra. El Conde tuvo que llamarle la atención, a su pesar, de que "no siguiera vaciando casas". Castera contestó que eran tan pocas las que había vaciado que no valía la pena, "que la única importante era una bizcochería detrás de San Hipólito..."

Del Mazo, muy prudente, entre unas autoridades y otras, propuso a Castera que, para mejor inteligencia del proyecto ya en la práctica, "pusiera unas señales o lineas gruesas perpendiculares con lechada o alma- 
gre en las casas que se deban cortar para que con facilidad se venga en conocimiento cuales son las que se han de derrumbar del todo y cuales en parte, para que de uno u otro modo se haga la graduación de ello".

El expediente termina con varias quejas de inquilinos amenazados o lanzados por Castera $y$ aun algunos por derrumbes forzosos. $Y$ en estas quejas se queda el documento del Archivo, y la ciudad, según nos consta, también se quedó igual. Don Ignacio de Castera fracasó. $Y$ tal vez se deba esto, más que a todo, a la muerte de su protector el Conde de Revillagigedo.

Con la continuación de las calles del centro, que, en realidad, no es sino continuar bien la traza inicial de Alonso García Bravo, el alarife constructor del México virreinal, no destruía Castera gran cosa, salvo en el lado norte de la Alameda, en donde sólo quedan las calles que van de norte a sur y todas las de oriente a poniente serian nuevas, hendiendo por mitad las alargadas o caprichosas manzanas que se habían formado y que, por cierto, todavía perduran en parte.

Quedaría íntegra la calle de San Juan de Letrán, que Castera dibuja mejorándola, pero arremete contra Santa Brígida, con la misma intención con que se abrió después la primera calle de Independencia actual. Claro está que no se atrevió a proponer la apertura del convento de San Francisco, por lo cual quedaba con su callejón oblicuo a la calle de Capuchinas. No dibujó los destrozos que sufriría en la parte posterior, el convento de Corpus Christi y destruye casi totalmente todas las manzanas del lado sur de la Alameda hasta lo que es hoy calle del Ayuntamiento.

Por el lado norte de la ciudad, detrás del convento de Santo Domingo, al cual no le respeta la cuchilla que se alargaba ( $y$ aun hoy, hecha cașas particulares) hasta la calle del Perú y hace trizas todo, de tal manera que sería completamente nueva esa parte de la ciudad; lo mismo pasa al poniente, si bien es cierto que la cuadricula de la vieja ciudad sale más favorecida por haber menor anarquía en su trazo.

Por el sur la calle respetada es la que corre detrás del convento de San Jerónimo, entroncando con San Juan de Letrán. Lo demás nuevo todo.

La idea de Castera nos parece inteligente y audaz para su época, como también imposible de efectuarse por los avanzados tiempos (albores de la Independencia) en que fué concebida. Pero, justamente, es esto lo interesante: es una de tantas expresiones de "modernidad" del espíriti 
neoclásico que no soportaba el viejo México barroco. La "razón" clásica imponía un México rectilineo, a la fuerza, enmendando todo yerro anterior. Asi como Tolsá y Tresguerras destruían los retablos barrocos, las torres retorcidas y las cúpulas de azulejos, Castera destruía a la antigua ciudad y planteaba un futuro que, en parte, se ha realizado. $Y$ se ha realizado a veces bien $y$ a veces mal. Pero toca la gloria de haber iniciado una urbanística moderna, cuando menos en teoría, al activo arquitecto don Ignacio de Castera. 